\title{
Evaluation of Dissolution Media Containing a Novel Synthetic Surfactant by In Vitro Testing of BCS Class II Drugs
}

\author{
Hitesh Jogia ${ }^{1,2,3}$, Tushar Mehta ${ }^{2}$, and Madhabhai Patel ${ }^{1}$ \\ ${ }^{1}$ Kalol Institute of Pharmacy, Kalol District, Gujarat-382 711, India \\ ${ }^{2}$ Analytical Development Laboratory, Torrent Research Center, c/o Torrent Pharmaceutical Ltd., \\ Nr. Indira Bridge, Bhat, Gandhinagar District, Gujarat-382 428, India
}

\begin{abstract}
The objective of this study was to employ a tailor-made, surface-active agent (phosphonobile acid) in the design of dissolution media that more closely reflect various luminal fluid physicochemical parameters such as buffer capacity, osmolarity, surface tension, and pH.The proposed media are simple to prepare and use, and thus can be explored for routine application. Three BCS II drugs, glimepiride, dipyridamole, and ibuprofen, were selected for the study. In vitro dissolution profiles obtained with the proposed media were compared with profiles obtained in FaSSIF and FeSSIF media using the $f_{2}$ similarity factor. Dissolution in the proposed media correlate well with the dissolution obtained in FaSSIF and FeSSIF media.
\end{abstract}

\section{INTRODUCTION}

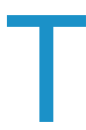

he science of dissolution is centuries old, and the application of dissolution testing is very important during drug development and the submission process for NDA and ANDA filings. Dissolution of drugs from oral solid dosage forms is a necessary criterion for drug bioavailability (i.e., the drug must be solubilized in the aqueous environment of the gastrointestinal tract to be absorbed). Therefore, the dissolution test for solid oral drug products has emerged as one of the most important control tests for assuring product uniformity and batchto-batch bioequivalence once bioavailability has been defined. Various pharmacopoeias suggest that the dissolution characteristics of an oral formulation should be evaluated in the physiologic $\mathrm{pH}$ range of 1.2-6.8 (1.2-7.5 for modified-release formulations) (1). However, poorly water-soluble compounds fail to solubilize in dissolution media over the entire $\mathrm{pH}$ range of 1.2-6.8.

The determination of dissolution profiles of waterinsoluble or sparingly water-soluble compounds requires dissolution media different from those normally used for water-soluble drugs. Water-insoluble or sparingly water-soluble drug products are most likely to solubilize in the presence of the naturally occurring surfactant and micellar media of the gastrointestinal tract. Buri et al. (2) demonstrated the similarity of natural surfactants (sodium cholate and taurocholate) to sodium lauryl sulfate (SLS) for the purpose of drug solubilization. The dissolution of water-insoluble and sparingly watersoluble drug dosage forms was studied with the use of surfactant-like SLS $(3,4)$; these reports suggest the use and importance of surfactants for in vitro dissolution studies.

${ }^{3}$ Corresponding author.
In addition to SLS, other surfactants like Tween or Span are also used in dissolution media for quality control tests (1). Routinely used dissolution media are mainly employed to check the batch-to-batch reproducibility of dosage forms. The designs of various reported dissolution media that have been characterized as "biorelevant media" were based on the physiological condition of the gastrointestinal tract containing sodium taurocholate as a surfactant (5-10). However, because of the high expense of these natural products, they are not practical to use in routine quality control tests. Use of SLS in dissolution media for poorly water-soluble drugs is based mainly on the solubilization capacity of this synthetic surfactant, but SLS lacks the physiological relevance of the gastrointestinal tract. Dissolution profiles obtained using synthetic surfactants like SLS may or may not exhibit IVIVC (4). To the best of our knowledge, synthetic surfactants with structural similarity to bile acids have not been reported.

In the present work, our primary aim was to select a synthetic surfactant that has structural similarity to bile acids. 24-Phosphonobile acid (24-PBS) was selected as a suitable candidate. The use of 24-PBS as a cholesterol gallstone solubilizer and its route of synthesis have been reported (11). The selected synthetic surfactant was used to design dissolution media that simulate the physiological properties of the luminal fluids such as buffer capacity, $\mathrm{pH}$, osmolarity, and surface tension. The evaluation of the proposed media was done using three BCS Class II drugs. The dissolution results obtained with the proposed media were statistically compared with the results obtained using two commonly used biorelevant dissolution media, Fasted-State Simulated Intestinal Fluid (FaSSIF) and Fed-State Simulated Intestinal Fluid (FeSSIF), using the $f_{2}$ similarity factor (12). 
Table 1. Drugs and Dosage Forms Used in This Study

\begin{tabular}{lll}
\hline Drug & $\mathbf{p}_{\mathbf{a}}$ & \multicolumn{1}{c}{ Dosage Form } \\
\hline Dipyridamole & 6.6 & $\begin{array}{l}\text { Dipyridamole Tablets } \\
(100 \mathrm{mg} / \mathrm{tab}) \\
\text { Lot No. }-003 \\
\text { Torrent Research Centre, India }\end{array}$ \\
\hline Glimepiride & & $\begin{array}{l}\text { Glimepiride Tablets } \\
\text { (4 mg/tab) } \\
\text { Lot No. -005 } \\
\text { Torrent Research Centre, India }\end{array}$ \\
\hline Ibuprofen & & $\begin{array}{l}\text { Ibuprofen Tablets } \\
\text { (200 mg/tab) } \\
\text { Lot No. -002 } \\
\text { Torrent Research Centre, India }\end{array}$ \\
\hline
\end{tabular}

\section{MATERIALS AND METHODS}

\section{Materials}

Lecithin (VWR International Ltd, England), cholic acid (National Chemical, India, 99\% purity), and sodium taurocholate (Sigma-Aldrich Chemie GmbH, USA, 97\% purity) were used. All reagents (potassium dihydrogen phosphate, sodium dihydrogen phosphate, sodium chloride, sodium acetate trihydrate, sodium hydroxide, hydrochloric acid) were of analytical grade (E Merck, India).

The drugs and dosage forms used in this study are presented in Table 1.

\section{Methods}

Synthesis of 24-Phosphonobile Acid

24-Phosphonobile acid was synthesized using cholic acid as precursor (11). The detailed route of synthesis is given in Figure 1. The structure of 24-phosphonobile acid was confirmed by IR, NMR, and mass spectrometry.

\section{Determination of Physicochemical Parameters}

Various physicochemical parameters of the proposed dissolution media were obtained as follows. The $\mathrm{pH}$ values were measured using a digital $\mathrm{pH}$ meter (Lab India
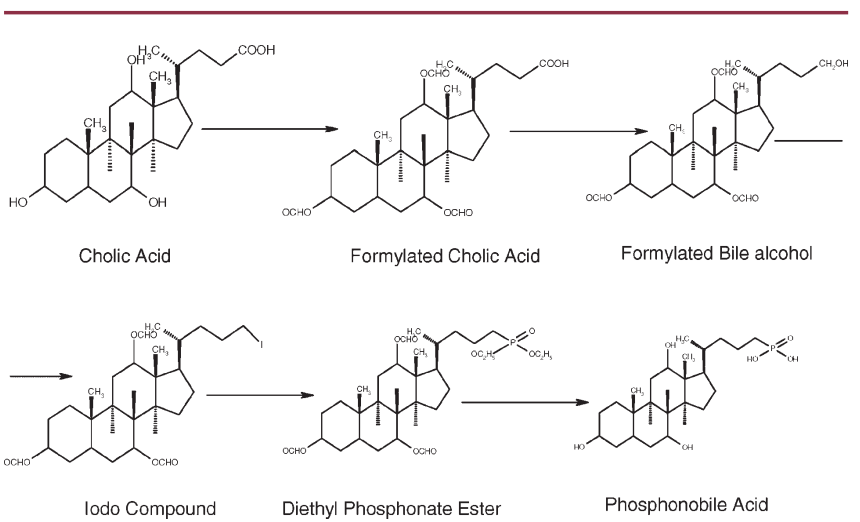

Figure 1. Route of synthesis of 24-PBS. instruments, India). Osmolality was determined by freezing-point depression using an automatic osmometer (Advance Instruments, USA). Buffer capacity was determined by titration with $1 \mathrm{M}$ hydrochloric acid (13). Surface tension was measured using a stalagnometer.

\section{Composition of Media}

The biorelevant dissolution media, FaSSIF and FeSSIF, were prepared based on available data (14). The detailed compositions of the proposed dissolution media (i.e., Proposed Media 1 [PM-1] and Proposed Media 2 [PM-2]) are represented in Table 2.

\section{Dissolution Test}

The dissolution studies were performed with USP Apparatus 2 (Varian Vankel, USA) employing $500 \mathrm{~mL}$ of dissolution media at $37 \pm 0.5^{\circ} \mathrm{C}$ and a stirring rate of 50 rpm. A sample of approximately $10 \mathrm{~mL}$ was removed from each vessel using a cannula attached to a syringe (Becton Dickinson, USA) and was replaced immediately with approximately $10 \mathrm{~mL}$ of fresh medium at $37 \pm 0.5^{\circ} \mathrm{C}$. The samples were filtered through $0.45-\mu \mathrm{m}$ filters and assayed by HPLC.

\section{Assay Methods}

The assays of ibuprofen and glimepiride were performed by HPLC using a Waters Symmetry $C_{18}$ column $(150 \times$ $4.6 \mathrm{~mm}, 5-\mu \mathrm{m}$ particle size). The mobile phase consisted of $0.01 \mathrm{M}$ potassium dihydrogen phosphate $(\mathrm{pH} 2.5) /$ acetonitrile $(50 / 50, \mathrm{v} / \mathrm{v})$. The flow rate was $1.5 \mathrm{~mL} / \mathrm{min}$. The effluent was monitored at $236 \mathrm{~nm}$ for glimepiride and $214 \mathrm{~nm}$ for ibuprofen.

Table 2. Composition of Proposed Dissolution Media, PM-1 and PM-2 ${ }^{a}$

\begin{tabular}{|c|c|c|}
\hline & PM-1 & PM-2 \\
\hline $\mathrm{pH}$ & 6.5 & 5.0 \\
\hline Osmolarity & 140 mOsmol kg-1 & $272 \mathrm{mOsmol} \mathrm{kg}^{-1}$ \\
\hline Buffer capacity & $13\left(\mathrm{mmol} \mathrm{L}^{-1} \Delta \mathrm{pH}^{-1}\right)$ & $29\left(\mathrm{mmol} \mathrm{L}^{-1} \Delta \mathrm{pH}^{-1}\right)$ \\
\hline Surface tension & $35 \mathrm{~N} \mathrm{~m}^{-2}$ & $30 \mathrm{~N} \mathrm{~m}^{-2}$ \\
\hline 24-phosphonobile acid & $3 \mathrm{mM}$ & $15 \mathrm{mM}$ \\
\hline $\begin{array}{l}\text { Sodium dihydrogen } \\
\text { phosphate }\end{array}$ & $0.025 \mathrm{M}$ & - \\
\hline Sodium acetate & - & $0.05 \mathrm{M}$ \\
\hline Sodium chloride & $2 \mathrm{~g}$ & $5 \mathrm{~g}$ \\
\hline Sodium hydroxide q.s. & $\mathrm{pH} 6.5$ & \\
\hline Acetic acid & & $\mathrm{pH} 5.0$ \\
\hline Deionized water & $1 \mathrm{~L}$ & $1 \mathrm{~L}$ \\
\hline
\end{tabular}

${ }^{a}$ Freshly prepared media were used in all cases. 


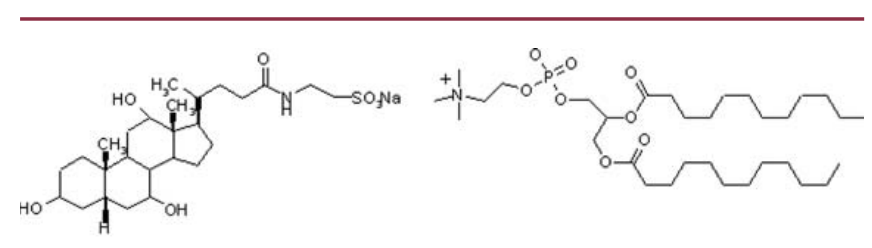

(a)

(b)

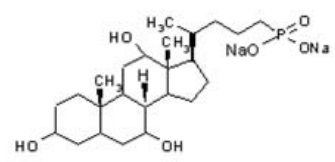

(c)

Figure 2. Chemical structure of (a) sodium taurocholate, (b) phosphatidylcholine, and (c) 24-phosphonobile acid.

The assay of dipyridamole was performed by HPLC using a Waters Symmetry $C_{18}$ column $(150 \times 4.6 \mathrm{~mm}, 5-\mu \mathrm{m}$ particle size) using a mobile phase of $0.01 \mathrm{M}$ potassium dihydrogen phosphate ( $\mathrm{pH} 3.0) /$ methanol/acetonitrile $(37 / 55 / 08, \mathrm{v} / \mathrm{v} / \mathrm{v})$. The flow rate was $1.0 \mathrm{~mL} / \mathrm{min}$. Detection was performed at $290 \mathrm{~nm}$. All assay methods were validated for their intended purpose.

Comparison of Dissolution Profiles

In vitro dissolution profiles were compared using the $f_{2}$ similarity factor.

$$
f_{2}=50 \log \left\{\left[1+\frac{1}{n} \sum_{t=1}^{n}\left(R_{t}-T_{t}\right)^{2}\right]^{-0.5} \times 100\right\}
$$

where $n$ is the number of dissolution sample times, and $R_{t}$ and $T_{t}$ are the individual or mean percent dissolved at each time point, $t$, for the reference and test dissolution profiles, respectively.

\section{RESULTS AND DISCUSSION}

The use of surfactants in the dissolution media for water-insoluble drug products may be physiologically more meaningful because natural surfactants such as bile acids, bile salts, and lecithin are normally present in the gastrointestinal tract. Shah et al. (4) concluded that the use of a surfactant system like SLS in dissolution media for poorly water-soluble compounds is more relevant to the in vivo situation than hydroalcoholic media and is a better quality control tool to check product consistency. To mimic the condition of in vivo gastric fluid, Galia et al. (6) proposed biorelevent dissolution media that contained sodium taurochlolate as the major natural surfactant. They successfully obtained in vivo-in vitro correlation for some Class I and Class II drugs. Biorelevant dissolution media are generally used for initial drug development, but their use in routine quality control (QC) testing is limited. QC media for the dissolution of poorly water-soluble drugs typically lack physiological relevance.

Table 3. Dissolution Profile Comparison of Three Model Drugs with $f_{2}$ Values

\begin{tabular}{|c|c|c|c|c|c|c|c|}
\hline \multirow[b]{2}{*}{ Drug and $f_{2}$ Value } & \multirow[b]{2}{*}{ Medium } & \multicolumn{6}{|c|}{$\%$ of Drug Released at Following Time Points (min) } \\
\hline & & 5 & 10 & 15 & 30 & 60 & 90 \\
\hline Dipyridamole & FaSSIF & 2.3 & 6.9 & 11.8 & 18.2 & 24.7 & 28.1 \\
\hline $\boldsymbol{f}_{2}=53.7$ & PM-1 & 2.9 & 5.4 & 7.4 & 9.9 & 12 & 15.1 \\
\hline Glimepiride & FaSSIF & 44.2 & 54.5 & 59.4 & 63.1 & 67.7 & 64.1 \\
\hline$f_{2}=65.8$ & PM-1 & 41.4 & 61.2 & 64.1 & 66.6 & 68.4 & 70.9 \\
\hline Ibuprofen & FaSSIF & 0.9 & 8.9 & 18.4 & 40.7 & 56.3 & 66 \\
\hline$f_{2}=66.8$ & PM-1 & 0.5 & 4.7 & 12.8 & 32.5 & 55.5 & 68.2 \\
\hline Dipyridamole & FeSSIF & 5 & 30 & 60 & 87 & 97.2 & 98.2 \\
\hline$f_{2}=61.1$ & PM-2 & 3 & 25.5 & 48.6 & 80.2 & 94.4 & 97 \\
\hline Glimepiride & FeSSIF & 44.7 & 59.9 & 65.8 & 71.7 & 86.9 & 89.3 \\
\hline$f_{2}=46.1$ & PM-2 & 65.8 & 70.4 & 75.8 & 83.3 & 90.7 & 96.5 \\
\hline Ibuprofen & FeSSIF & 8.1 & 17.9 & 31 & 66.4 & 75.6 & 82.5 \\
\hline$f_{2}=57.0$ & PM-2 & 2.6 & 22.7 & 43.2 & 71.3 & 83.9 & 86.3 \\
\hline Dipyridamole & FeSSIF & 5 & 30 & 60 & 87 & 97.2 & 98.2 \\
\hline$f_{2}=61.1$ & PM-2 & 3 & 25.5 & 48.6 & 80.2 & 94.4 & 97 \\
\hline
\end{tabular}


In the present study, an attempt was made to explore the use of dissolution media containing a novel synthetic surfactant that has structural similarity to bile acids and could closely mimic the physicochemical properties of the luminal fluids of the small intestine. We also attempted to provide a robust quality control dissolution test using these proposed media.

\section{Selection of Surfactant}

Structural similarity of the proposed surfactant to bile acids was a prime requirement for its selection for the dissolution studies. 24-PBS (Figure 2c) has cyclopentanophenethrene as a nonpolar backbone, which resembles the bile acid sodium taurocholate (Figure 2a), as well as a phosphone linkage (polar head), which is similar to lecithin (Figure 2b). In addition, 24-phosphonobile acid has been reported as a cholesterol gallstone solubilizer (11); hence, 24-PBS was selected as a suitable surfactant for the above-mentioned purpose. The concentrations of 24-PBS in the dissolution media preparation were $3 \mathrm{mM}(\mathrm{PM}-1)$ and $15 \mathrm{mM}(\mathrm{PM}-2)$, simulating fasted- and fed-state conditions of small intestine, respectively (14).

\section{Design of Proposed Dissolution Media}

Design and preparation of the proposed dissolution media containing the synthetic surfactant were based on the physicochemical properties of the small intestine in fasted- and fed-state conditions, viz. buffer capacity, osmolarity, $\mathrm{pH}$, and surface tension. The $\mathrm{pH}$ values of proposed media were adjusted to 6.5 and 5.0 for PM-1 and PM-2, respectively, based on reported $\mathrm{pH}$ values for FaSSIF and FeSSIF (14). Osmolarities of the proposed media were adjusted based on reported values of fasted $\left(142 \mathrm{mOsm} \mathrm{kg}{ }^{-1}\right)$ (15) and fed (287 mOsm kg ${ }^{-1}$ ) (16) duodenal secretion. Sodium chloride was used to adjust the osmolarity (17). Buffer capacities of the proposed media were adjusted using sodium dihydrogen phosphate and sodium acetate for PM-1 and PM-2, respectively. In addition, the surface tensions of the proposed media were measured, and the obtained values were in accordance with published details about surface tension of fasted $\left(32.3 \mathrm{mN} \mathrm{m}^{-2}\right)$ and fed $\left(28.8 \mathrm{mN} \mathrm{m}^{-2}\right)$ duodenum content (16). Complete compositional details of the proposed media are listed in Table 2.

For the in vitro evaluation of the proposed surfactant in dissolution media, tablet formulations of the BCS Class II drugs glimepiride, ibuprofen, and dipyridamole were selected because dissolution of BCS II drugs is the rate-limiting step for absorption. Dissolution of Class II drugs also depends on a wide variety of factors such as surfactant, buffer capacity, $\mathrm{pH}$, and ionic strength (6). The FaSSIF and FeSSIF dissolution media were selected as references for comparison of the dissolution profiles of glimepiride, ibuprofen, and dipyridamole in the proposed media because they represent media that are physiologically relevant to intestinal fluid (6) and because the natural surfactant (sodium taurochlolate) used in FaSSIF and FeSSIF is structurally similar to 24-PBS (synthetic surfactant).

The in vitro dissolution tests were performed as stated in Materials and Methods for three BCS Class II drug formulations (Table 1) in the proposed dissolution media (PM-1 and PM-2), FaSSIF, and FeSSIF. The release of each drug in all four media was compared statistically using the $f_{2}$ similarity factor. The in vitro drug release profiles obtained for the three drugs in PM-1 were compared with FaSSIF, and those obtained using PM-2 were compared with FeSSIF. The results are tabulated in Table 3 and graphically represented in Figures 3 and 4.

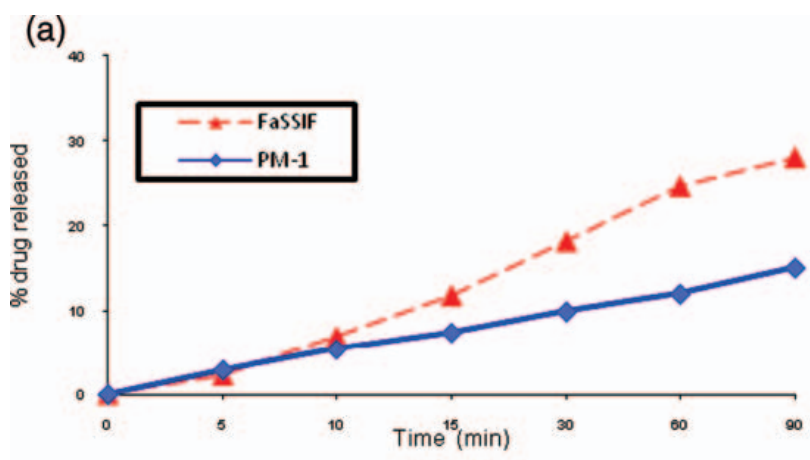

(b)

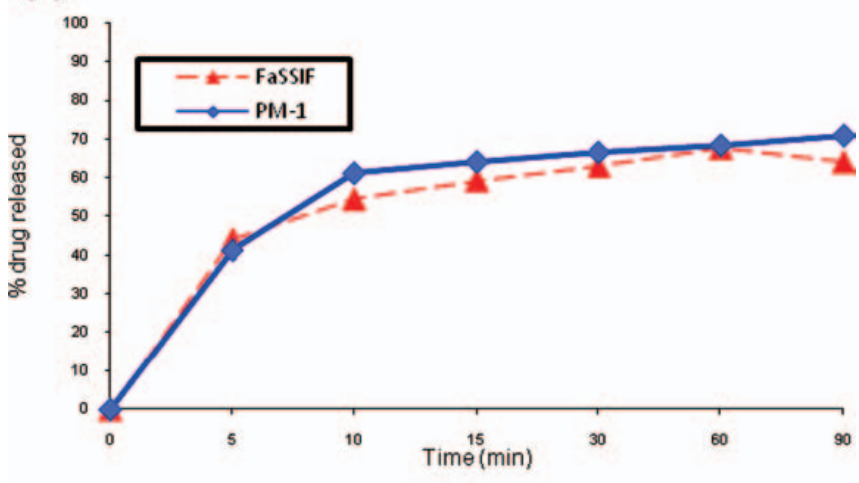

(c)

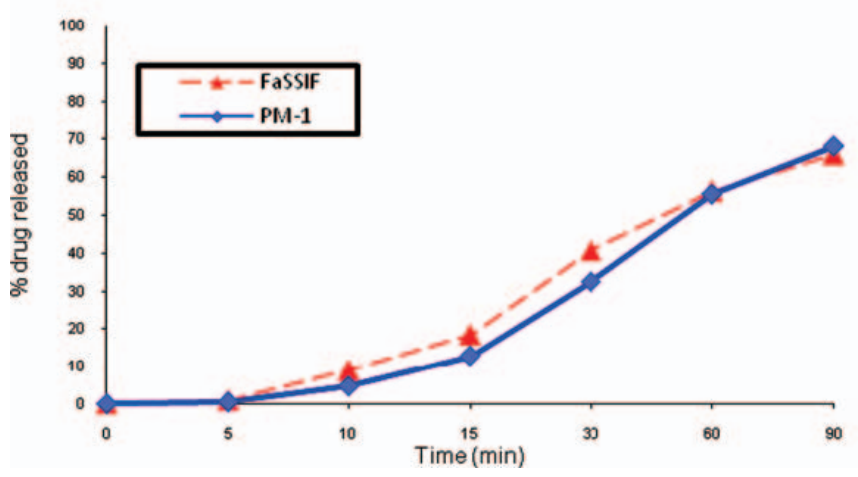

Figure 3. Dissolution profile comparison of FaSSIF vs PM-1 for (a) dipyridamole, (b) glimepiride, and (c) ibuprofen. 
(a)

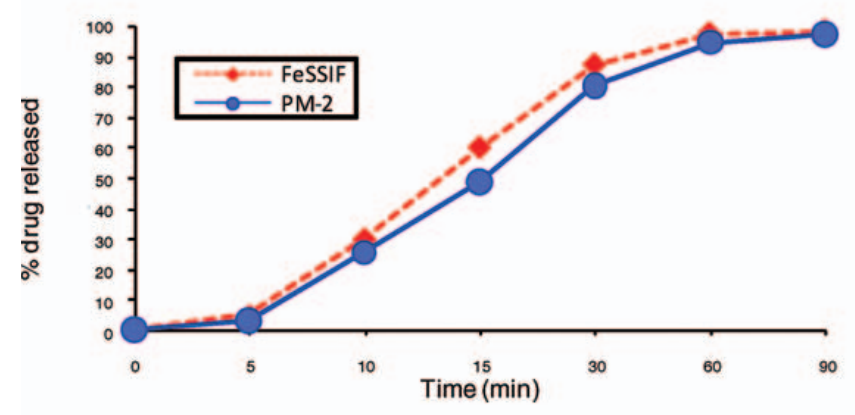

(b)

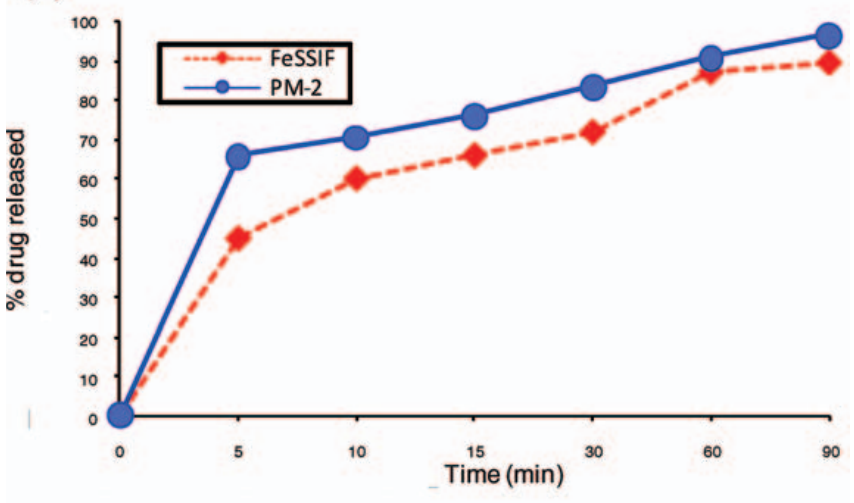

(c)

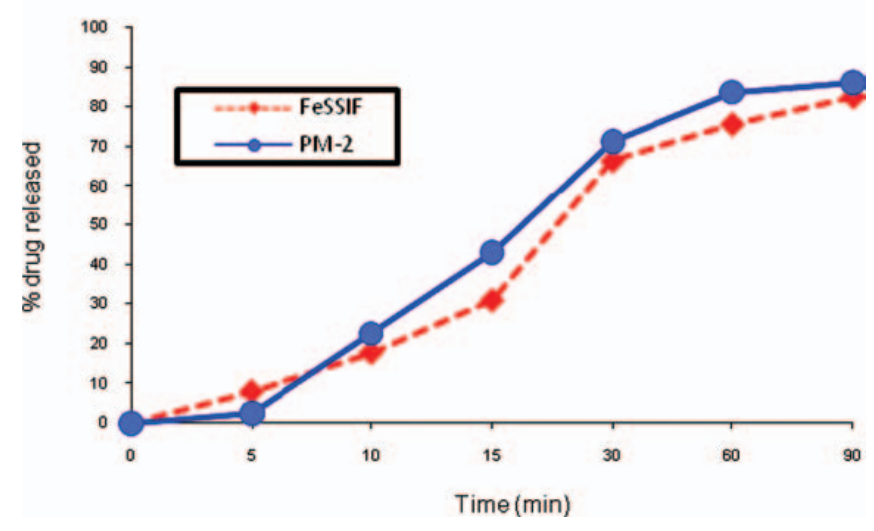

Figure 4. Dissolution profile comparison of FeSSIF vs PM-2 for (a) dipyridamole, (b) glimepiride, and (c) ibuprofen.

The $f_{2}$ values obtained from the comparison of dissolution profiles of the three BCS II drugs in PM-1 and PM-2 versus reported media (FaSSIF and FeSSIF) were nearly all greater than 50 , indicating similarity between the proposed and reported media in terms of drug release. The one exception $\left(f_{2}=46\right)$, obtained from glimepiride tablet dissolution in PM-2 and FeSSIF, was the result of the lower dissolution in FeSSIF, which was an artifact attributed to degradation of glimepiride in FeSSIF. Dipyridamole is a weak base with a $\mathrm{p} K_{\mathrm{a}}$ of 6.4 , hence it exhibits low solubility at $\mathrm{pH}$ 6.5. The dose-to-solubility ratio of dipyridamole in FaSSIF is $8 \mathrm{~L}(10)$. For this reason, the release of dipyridamole in PM-1 and FaSSIF is very low. The similarity between the dissolution profiles in the proposed media and those in FaSSIF/FeSSIF media is presumably due to similarity between the synthetic surfactant (24-PBS) and sodium taurocholate. Preparation of PM-1 and PM-2 media was simple, giving them a definite advantage for use as routine QC release media having physicochemical biorelevancy. The results lead the authors toward further exploration of the proposed media in predicting in vivo drug release of other formulation with BCS Class II drugs. Further scope of research will be to establish IVIVC using the proposed media.

\section{CONCLUSION}

A tailor-made surfactant (24-PBS) was synthesized, characterized, and used to prepare PM-1 and PM-2 dissolution media. The proposed dissolution media using this synthetic surfactant were designed to closely mimic the physicochemical properties of the small intestine. The dissolution data obtained for model BCS Class II drugs using the proposed media were compared with those from FaSSIF and FeSSIF media. The dissolution profiles from the proposed media were similar to those from FaSSIF and FeSSIF in most cases.

\section{REFERENCES}

1. Dissolution $<711>$. In United States Pharmacopeia and National Formulary USP 29-NF 24; The United States Pharmacopeial Convention, Inc.: Rockville, MD, 2007; pp 277-284.

2. Buri, P.; Humbert-Droz, J. Solubilization de principes actif insolubles par des constituants des sucs digestifs. In Proceedings of the 3rd International Congress of Pharmaceutical Technology; Paris, 1983; Vol. 4, pp 136-143.

3. Shah, V. P.; Konecny, J. J.; Everett, R. L.; McCullough, B.; Noorizadeh, A. C.; Skelly, J. P. In vitro dissolution profile of water-insoluble drug dosage forms in the presence of surfactants. Pharm. Res. 1989, 6, 612-618.

4. Shah, V. P; Noory, A.; Noory, C.; McCullough, B.; Clarke, S.; Evertt, R.; Naviasky, H.; Srinivasan, B. N.; Fortman, D.; Skelly, J. P. In vitro dissolution of sparingly watersoluble drug dosage forms. Int. J. Pharm. 1995, 125, 99-106.

5. Galia, E.; Nicolaides, E.; Reppas, C.; Dressman, J. B. New media discriminate dissolution properties of poorly soluble drugs. Pharm. Res. 1996, 13 (Supplement), S-262.

6. Galia, E.; Nicolaides, E.; Horter, D.; Lobenberg, R.; Reppas, C.; Dressman, J. B. Evaluation of various dissolution media for predicting in vivo performance of class I and class II drugs. Pharm. Res. 1998, 15, 698-705. 
7. Nicolaides, E.; Galia, E.; Efthymiopoulos, C.; .Dressman, J. B.; Reppas, C. Forecasting the in vivo performance of four low solubility drugs from their in vitro dissolution data. Pharm. Res. 1999, 16, 1876-1882.

8. Dressman, J. B.; Reppas, C. In vitro-in vivo correlations for lipophilic, poorly water-soluble drugs. Pharm. Res. 2000, 93, 91-100.

9. Nicolaides, E.; Symillides, M.; Dressman, J. B.; Reppas, C. Biorelevant dissolution testing to predict the plasma profile of highly lipophilic drugs after oral administration. Pharm. Res. 2001, 18, 380-388.

10. Kostewicz, E.; Brauns, U.; Becker, R.; Dressman, J. B. Forecasting the oral absorption behavior of poorly soluble weak bases using solubility and dissolution studies in biorelevant media. Pharm. Res. 2002, 19, 345-349.

11. Babu, P.; Maitra, U. Synthesis and in vitro cholesterol dissolution by 23- and 24-phosphonobile acids. Steroids 2005, 70, 681-689.

12. Moore, J. W.; Flanner, H. H. Mathematical comparison of dissolution profiles. Pharm. Technol. 1996, 20, 64-74.
13. Perez de la Cruz Moreno, M.; Oth, M.; Deferme, S.; Lammert, F.; Tack, J.; Dressman, J.; Augustijns, P. Characterization of fasted-state human intestinal fluids collected from duodenum and jejunum. $J$. Pharm. Pharmacol. 2006, 58, 1079-1089.

14. Marques, M. Dissolution media simulating fasted and fed states. Dissolution Technol. 2004, 11, 16.

15. Gisolfi, C. V.; Summers, R. W.; Lambert, G. P.; Xia, T. Effect of beverage osmolarity on intestinal fluid absorption during exercise. J. Appl. Physiol. 1998, 85, 1941-1948.

16. Kalantzi, L.; Goumans, K.; Kalioras, V.; Abrahamsson, B.; Dressman, J. B.; Reppas, C. Characterization of the human upper gastrointestinal contents under conditions simulating bioavailability/bioequivalence studies. Pharm. Res. 2006, 23, 165-176.

17. Vertzoni, M.; Fotaki, N.; Kostewicz, E.; Stippler, E.; Leuner, C.; Nicolaides, E.; Dresman, J. B. Dissolution media simulating the intralumenal composition of the small intestine. J. Pharm. Pharmacol. 2004, 56, 453-462.

\section{PROUDLY ANNOUNCING NEW TECHNOLOGY, ADVANCING DISSOLUTION TEST ACCURACY}

\section{UltraCenter ${ }^{\mathrm{TM}}$ Dissolution Systems}

UliraCenter TM Dissolution Systems (PATENT PENDING) offer ulimate control of Dissolution variables and assist with easy Dissolution Instrument Calbration to ASTM E 2503-07 requirements. Individual compo-

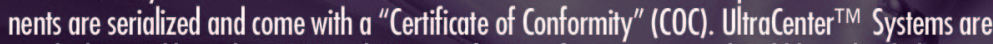
supplied Pre-Calbrated to ASTM and USP specifications for Centering and Wobble and include a "Mechanical Callbration Report Sheet" for Centering and Wobble.

UliraCenter TM Vessel Specifications: UliraCenter ${ }^{\mathrm{TM}}$ System Specilications:

Vessel Inside Diameter Tolerance $=+$ or $-.005 \mathrm{in} / .13 \mathrm{~mm}$

Vessel Spherical Radius Tolerance $=+$ or $-.005 \mathrm{in} / .13 \mathrm{~mm}$

- Flange Perpendicularity Tolerance $=.020 \mathrm{in} / .50 \mathrm{~mm}$ TIR max
Centering Tolerance $=.020$ in $/ .50 \mathrm{~mm}$ max

Shaft Wobble Tolerance $=.010 \mathrm{in} / .25 \mathrm{~mm}$ max

Basket Wobble Tolerance $=.040 \mathrm{in} / 1.00 \mathrm{~mm}$ max

$\square$ Paddle / Basket Height Tolerance $=+$ or $-.020 \mathrm{in} / .50 \mathrm{~mm} \max$

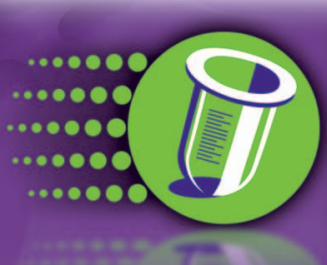

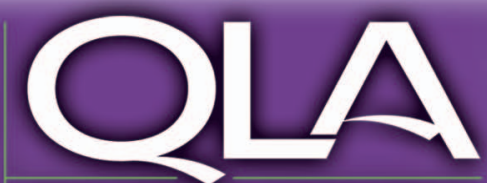

QUALITY LAB ACCESSORIES
Visit us at AAPS Booth\#2351 and EAS Booth \#726

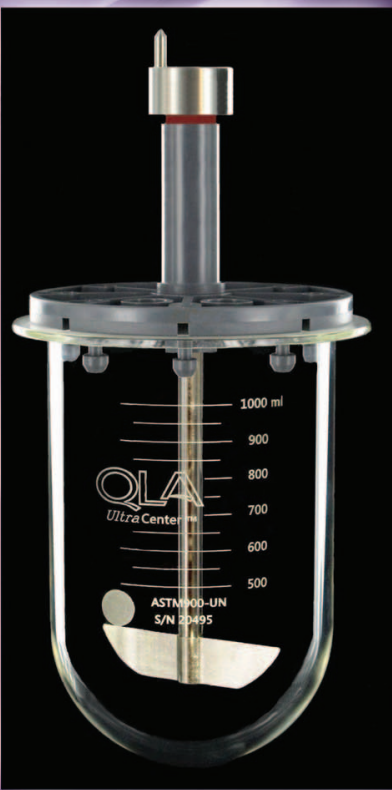

BRIDGEWATER, NJ・PH: $908-685-7500 \cdot w$ w w. I a-I Ic.com 